\section{Electroconvulsive therapy hasn't negative effects on short-term memory function, as assessed using a bedside hand-held device}

\author{
Helge H.O. Müller,1,2 Mareen Reike, ${ }^{1}$ \\ Simon Grosse-Holz, ${ }^{1}$ Mareike Röther, ${ }^{1}$ \\ Caroline Lücke, ${ }^{2}$ Alexandra Philipsen, ${ }^{2}$ \\ Johannes Kornhuber, ${ }^{1}$ Teja W. Grömer ${ }^{1}$ \\ 1Department of Psychiatry and \\ Psychotherapy, Friedrich-Alexander \\ University Erlangen-Nuremberg, \\ Erlangen; 2Department of Psychiatry \\ and Psychotherapy, Medical Campus \\ University of Oldenburg, School of \\ Medicine and Health Sciences, \\ University Hospital Karl-Jaspers-Klinik, \\ Bad Zwischenahn, Germany
}

\begin{abstract}
Electroconvulsive therapy (ECT) is effective in the treatment of treatment-resistant major depression. The fear of cognitive impairment after ECT often deters patients from choosing this treatment option. There is little reliable information regarding the effects of ECT on overall cognitive performance, while short-term memory deficits are well known but not easy to measure within clinical routines. In this pilot study, we examined ECT recipients' pre- and posttreatment performances on a digital ascending number tapping test. We found that $\operatorname{cog}$ nitive performance measures exhibited good reproducibility in individual patients and that ECT did not significantly alter cognitive performance up to 2 hours after this therapy was applied. Our results can help patients and physicians make decisions regarding the administration of ECT. Digital measurements are recommended, especially when screening for the most common side effects on cognitive performance and short-term memory.
\end{abstract}

\section{Introduction}

Major depressive disorder (MDD) is a chronic mood disorder that affects over 350 million patients worldwide. In the European Union, reported prevalence rates of up to $6.9 \%$ and lifetime prevalences of $16-20 \%$ indicate that this disease is a prominent socioeconomic problem. ${ }^{1-3}$ Despite the availability of numerous psychopharmacological treatments, strong evidence indicates that only $60-70 \%$ of persons who tolerate antidepressants will respond to first-line drug therapy for MDD.4-6 In cases involving no or partial response to drug treatment and high symptom severity, electroconvulsive therapy (ECT) is regarded as an effective acute treatment option for both unipolar and bipolar depression. ECT is highly effective, especially in treatment-resistant depressive disorders (TRD); in particular, ECT achieves remission rates of $50-80 \%$ and is considered the gold standard in neurostimulation treatment for MDD. 1,3,4,7-11 However, in addition to excellent clinical response rates, ECT also has serious side effects. First, major characteristics of the ECT neurocognitive profile include transiently decreased orientation and impaired short-term memory function during ECT sessions. The reported ECT-induced cognitive impairment has a broad palette of different manifestations and typically consists of temporary anterograde (i.e., difficulties in acquiring and retaining new information) and/or retrograde amnesia (i.e., the impaired recall of information learned before ECT) or confusional symptoms, such as disorientation and attention deficits, in certain patients during relatively long periods over multiple days. These forms of impairment are more pronounced in cases involving bilateral electrode placement than in cases involving unilateral electrode placement. $12-19$ Reports have indicated that ECT can lead to inefficiency or impairment in various other neuropsychological domains, including speed of processing, attention, verbal fluency, and executive functions (e.g., cognitive flexibility). Up to $55 \%$ of patients also report that the aforementioned side effects persist for months after ECT.9,12,15,16,20-22 Prolonged confusional states might limit the use of ECT; in particular, at present, this issue is often reported as a subjective limitation during courses of ECT. Because the most common side effects of ECT are cognitive impairments that occur immediately after treatment, the use of a hand-held device in a bedside test setting seemed well suited to capture such effects. We also hypothesized that influencing factors such as age or gender could be relevant, and additional effects on the hypothesized cognitive decline due to medication and anesthesia were examined.

\section{Materials and Methods}

\section{Patient recruitment and ethical con- siderations}

Patients with MDD or major depressive episodes were recruited for this study, and all received written information and provid-
Correspondence: Helge Heinrich Oskar Müller, Department of Psychiatry, Carl von Ossietzky University Oldenburg, HermannEhlersstrasse 7, D-26160 Bad Zwischenahn, Germany.

Tel.: +49.441.9615.1507 - Fax: +49.441.9615.1599

E-mail: helge.mueller1@uni-oldenburg.de

Key words: ECT, cognitive impairment, cognitive performance.

Contributions: HHOM, MR, TWG, and JK designed the study. SGH, MR, and CL contributed to the data acquisition and statistical analyses. AP, JK, HHOM, and TWG approved the final draft of the manuscript. All authors contributed to writing the drafts of the manuscript and provided intellectual input within this project.

Conflicts of interest: the authors declare no potential conflict of interest.

Funding: this study received intramural funding from the Department of Psychiatry of the Friedrich-Alexander University of ErlangenNuremberg (Head of Department: Professor Dr. J. Kornhuber).

Received for publication: 14 February 2017. Revision received: 31 March 2017.

Accepted for publication: 31 March 2017.

This work is licensed under a Creative Commons Attribution-NonCommercial 4.0 International License (CC BY-NC 4.0).

(C) Copyright H.H.O. Müller et al., 2017

Licensee PAGEPress, Italy

Mental Illness 2017; 9:7093

doi:10.4081/mi.2017.7093

ed informed consent to participate. All probands were diagnosed via structured clinical interviews and, in some cases, via clinical judgement. None of the patients suffered from neurocognitive diseases or dementia. Prolonged confusional states might limit the use of ECT; in particular, this issue is often reported as a subjective limitation during courses of ECT.

Patients often report ECT-associated cognitive impairment subjectively; therefore, an objective assessment is required.2326 A recent report by our group addressed the usefulness and practicability of psychometric measurements obtained using a hand-held device;27 thus, this study was conducted using this innovative hand-held device-based rating instrument. We used a digital ascending number tapping test (DANTT), which is based on the validated Trail Making Test A and digitally evaluates speed of processing, executive function and visual search, 28 to measure cognitive per- 
formance in short-term memory function domains shortly before and shortly after ECT. The study was approved by the ethics committee of Friedrich-Alexander University Erlangen-Nuremberg. All participants provided written informed consent for the hand-held-based and hand-written assessments after they had received an oral explanation of the study.

\section{Study subjects}

A total of 20 patients (11 males and 9 females) suffering from MDD (diagnosed based on structured clinical interviews according to the Diagnostic and Statistical Manual of Mental Disorders IV-Text Revision of the American Psychiatric Association) ${ }^{29}$ who received ECT as part of their clinical treatment participated in this study. The patients' mean age was 48.8 years (SD 9.961 years, range 36-76 years); $60 \%$ of the patients had suffered from an acute depressive episode as part of recurrent major depression, $30 \%$ of the patients had a depressive episode within bipolar disorder, and $10 \%$ of the patients had a schizoaffec- tive disorder. All patients were taking psychoactive medication as part of their treatment during the course of the experiment. The most frequently taken drugs were atypical neuroleptics (75\% of patients) and SSRIs (35\% of patients).

The control group consisted of 20 patients who were suffering from an acute depressive episode but were not treated with ECT. A complete overview of the demographic characteristics and medications of the ECT and control patients is provided in Table 1.

\section{Table 1. Demographic characteristics of the study subjects.}

\begin{tabular}{|c|c|c|c|c|c|c|}
\hline & \multicolumn{3}{|c|}{ ECT group } & \multicolumn{3}{|c|}{ Control group } \\
\hline & Mean & Count & N (\%) & Mean & Count & $\mathbf{N}(\%)$ \\
\hline Age & 48.8 & & & 55.6 & & \\
\hline $\begin{array}{l}\text { Gender } \\
\quad \text { Male } \\
\text { Female }\end{array}$ & & $\begin{array}{c}11 \\
9\end{array}$ & $\begin{array}{l}55.0 \\
45.0\end{array}$ & & $\begin{array}{c}8 \\
12\end{array}$ & $\begin{array}{l}40.0 \\
60.0\end{array}$ \\
\hline $\begin{array}{l}\text { Diagnosis } \\
\text { Major depression, }{ }^{*} \text { recurrent } \\
\text { Major depression, }{ }^{*} \text { single episode } \\
\text { Bipolar disorder, currently in a depressive episode* }\end{array}$ & & $\begin{array}{l}12 \\
0 \\
6\end{array}$ & $\begin{array}{c}60.0 \\
0.0 \\
30.0\end{array}$ & & $\begin{array}{l}12 \\
5 \\
1\end{array}$ & $\begin{array}{c}60.0 \\
25.0 \\
5.0\end{array}$ \\
\hline Schizoaffective disorder & & 2 & 10.0 & & 2 & 10.0 \\
\hline & & dicatio & & & & \\
\hline $\begin{array}{l}\text { Tricyclic antidepressants } \\
\text { No } \\
\text { Yes }\end{array}$ & & $\begin{array}{c}16 \\
4\end{array}$ & $\begin{array}{l}80.0 \\
20.0\end{array}$ & & $\begin{array}{c}17 \\
3\end{array}$ & $\begin{array}{l}85.0 \\
15.0\end{array}$ \\
\hline $\begin{array}{l}\text { SSRI } \\
\text { No } \\
\text { Yes }\end{array}$ & & $\begin{array}{c}13 \\
7\end{array}$ & $\begin{array}{l}65.0 \\
35.0\end{array}$ & & $\begin{array}{c}13 \\
7\end{array}$ & $\begin{array}{l}65.0 \\
35.0\end{array}$ \\
\hline $\begin{array}{l}\text { SNRI } \\
\text { No } \\
\text { Yes }\end{array}$ & & $\begin{array}{c}16 \\
4\end{array}$ & $\begin{array}{l}80.0 \\
20.0\end{array}$ & & $\begin{array}{c}12 \\
8\end{array}$ & $\begin{array}{l}60.0 \\
40.0\end{array}$ \\
\hline $\begin{array}{l}\text { MAO inhibitors } \\
\text { No } \\
\text { Yes }\end{array}$ & & $\begin{array}{c}18 \\
2 \\
\end{array}$ & $\begin{array}{l}90.0 \\
10.0 \\
\end{array}$ & & $\begin{array}{c}20 \\
0\end{array}$ & $\begin{array}{c}100.0 \\
0.0\end{array}$ \\
\hline $\begin{array}{l}\text { Typical antipsychotics } \\
\text { No } \\
\text { Yes }\end{array}$ & & $\begin{array}{c}16 \\
3\end{array}$ & $\begin{array}{l}84.2 \\
15.8\end{array}$ & & $\begin{array}{l}18 \\
2\end{array}$ & $\begin{array}{l}90.0 \\
10.0\end{array}$ \\
\hline $\begin{array}{l}\text { Atypical antipsychotics } \\
\text { No } \\
\text { Yes }\end{array}$ & & $\begin{array}{c}5 \\
15 \\
\end{array}$ & $\begin{array}{l}25.0 \\
75.0\end{array}$ & & $\begin{array}{c}9 \\
11 \\
\end{array}$ & $\begin{array}{l}45.0 \\
55.0\end{array}$ \\
\hline $\begin{array}{l}\text { Betablocker } \\
\text { No } \\
\text { Yes }\end{array}$ & & $\begin{array}{c}15 \\
5\end{array}$ & $\begin{array}{l}75.0 \\
25.0\end{array}$ & & $\begin{array}{c}16 \\
4\end{array}$ & $\begin{array}{l}80.0 \\
20.0\end{array}$ \\
\hline $\begin{array}{l}\text { L-thyroxine } \\
\text { No } \\
\text { Yes }\end{array}$ & & $\begin{array}{c}15 \\
5 \\
\end{array}$ & $\begin{array}{l}75.0 \\
25.0\end{array}$ & & $\begin{array}{c}14 \\
6 \\
\end{array}$ & $\begin{array}{l}70.0 \\
30.0\end{array}$ \\
\hline $\begin{array}{l}\text { Mirtazapine } \\
\text { No } \\
\text { Yes }\end{array}$ & & $\begin{array}{c}17 \\
3\end{array}$ & $\begin{array}{l}85.0 \\
15.0\end{array}$ & & $\begin{array}{c}14 \\
6\end{array}$ & $\begin{array}{l}70.0 \\
30.0\end{array}$ \\
\hline $\begin{array}{c}\text { Lithium } \\
\text { No } \\
\text { Yes } \\
\end{array}$ & & $\begin{array}{c}18 \\
2 \\
\end{array}$ & $\begin{array}{l}90.0 \\
10.0 \\
\end{array}$ & & $\begin{array}{c}15 \\
5\end{array}$ & $\begin{array}{l}75.0 \\
25.0\end{array}$ \\
\hline $\begin{array}{l}\text { Benzodiazepines } \\
\text { No } \\
\text { Yes }\end{array}$ & & $\begin{array}{c}15 \\
5\end{array}$ & $\begin{array}{l}75.0 \\
25.0\end{array}$ & & $\begin{array}{c}14 \\
6\end{array}$ & $\begin{array}{l}70.0 \\
30.0\end{array}$ \\
\hline $\begin{array}{l}\text { Antiepileptics } \\
\text { No } \\
\text { Yes }\end{array}$ & & $\begin{array}{c}16 \\
4\end{array}$ & $\begin{array}{l}80.0 \\
20.0\end{array}$ & & $\begin{array}{c}15 \\
5\end{array}$ & $\begin{array}{l}75.0 \\
25.0\end{array}$ \\
\hline
\end{tabular}

*All probands fulfilled the criteria of a moderate depressive episode (BDI: 20-28 points). 


\section{Test assessments}

We used a DANTT that assesses visual search, processing speed, and mental flexibility to determine whether ECT induces side effects on the domain of short-term memory function. ${ }^{28}$ In contrast to Trailmaking Test part A, the identification of numbers is not hindered by the line that the participant draws on the paper, and numbers are arranged in random places so that the test can be performed without the memorization of patterns. It also allows for a high time resolution and absolute precision in recording errors. The subjects were instructed to push on individual numbers from a set of 25 numbers in ascending order as rapidly as possible. Healthy subjects are supposed to complete this task in less than $25 \mathrm{sec}-$ onds; subjects who require more than 78 seconds for this task are regarded as having impaired cognition. 30

Beck's Depression Inventory (BDI) was used to measure depressive symptoms. This test assessment consists of 21 self-rated questions scored from 0-3 using a Likert scale. The questionnaire results were interpreted as follows: overall BDI scores of $<14,14-19,20-28$, and $>29$ were regarded as indicative of the least, minor, moderate, and major depressive symptoms, respectively. 31

\section{Electroconvulsive therapy procedure and sample treatment}

The participants completed exactly 10 assessments throughout the ECT treatment, which is the standard treatment procedure in the ECT ward. A baseline assessment (t0) was performed one day before the first ECT and was used as a comparison value against the post-ECT measurements. Post-ECT testing was performed on three separate days during which patients received ECT treatment ( $\mathrm{t} 1-\mathrm{t} 3)$. On each treatment day, three post-ECT measurements were obtained within a maximum of 2 hours after ECT (t1.1-t1.3, t2.1-t2.3, and t3.1-t3.3). In addition, BDI scores were assessed on each treatment day. For the ECT treatments (10 for each proband), the patients received intravenous (i.v.) anesthesia with $1 \%$ propofol $(0.5 \mathrm{mg} / \mathrm{kg})$, etomidate $(0.4 \mathrm{mg} / \mathrm{kg}$ i.v. $)$ and succinylcholine ( $1 \mathrm{mg} / \mathrm{kg}$ i.v.). We used a constant-current Thymatron System IV device (Somatics LLC, Lake Bluff, IL, USA) for stimulation. The right unilateral position was chosen in all patients. Stimulus parameters were initially set at 35\% energy and, if necessary, were increased to obtain adequate seizures. The pulse width was set at $0.5 \mathrm{~ms}$, and the stimulation frequency was $30 \mathrm{~Hz}$. This regime did not differ from the clinical standard procedure.

\section{Specific hand-held measurements}

Two apps (DANTT and BDI) for the Apple iPad 2 were developed by the experimenters for the hand-held tests in this study (Figure 1). At the beginning of every assessment, the patient was given the hand-held device and then completed the assessment on his or her own.

For the DANTT, every assessment consisted of two tests with only five numbers (with level 5 representing the least difficult task to learn) to familiarize the patient with the assessment's underlying concept (Figure 1A), followed by four repetitions of the actual test, each of which included 15 numbers (Figure 1B). The numbers on each test were arranged randomly to prevent the learning effect that occurs when the typical paper-based test is administered. If the patient touched a wrong number (or missed the correct one), the device indicated the mistake, as depicted in Figure 1C. On the test screens, the circled numbers had a diameter of $1.4 \mathrm{~cm}$; the test area (framed in black) was $13.6 \times 7.7 \mathrm{~cm}^{2}$ for the example tests and $13.6 \times 17.3 \mathrm{~cm}^{2}$ for the actual tests.

The app records the time and position of every touch of the screen, thereby allowing for a precise quantitative analysis of the patient's performance. At the end of each assessment, the results were sent under a pseudonym (that cannot be linked to a specific patient) to an e-mail account opened solely for this purpose.

The hand-held BDI functioned in a similar manner. When the patient was given the device, it displayed the explanatory screen depicted in Figure 2A. After the Accept and Continue button (in the lower right corner) was pressed, the BDI test began. An example of a BDI question is presented in Figure 2B. For every question, only one answer could be provided. The patient could navigate through questions using the Next and Previous buttons at the bottom of the page. For the BDI, similarly to the number tapping test, the patient's behavior (the time to answer each question, navigation events and the possible revision of an answer) was recorded, and data were sent via e-mail to a research account.

\section{Statistical procedures}

All statistical analyses were performed using SPSS Statistics 22 (IBM, Armonk, NY, USA). The statistical tests that were utilized are detailed in the Results section.

\section{Results}

\section{Performance times}

The mean normalized post-ECT performance time, as the primary outcome measure, was 0.961 (SD 0.164, range 0.571.26) relative to the pre-ECT reaction time of 1 . Thus, in contrast to the expected concentration-impairing effect of ECT, mean performance times tended to be lower after ECT sessions than before ECT. The Kolmogorov-Smirnov and Lilliefors tests indicated that the Performance times data did not deviate from normality $(\mathrm{P}<0.05)$. Repeated measures ANOVA (rmANOVA) was performed with the within-subject factor timepoint (with normalized average reaction time at the timepoint $\mathrm{t} 0$ as the baseline and the normalized average performance times at $\mathrm{t} 1.1-\mathrm{t} 3.3$ obtained after the 1 st, $2^{\text {nd }}$ or $3^{\text {rd }}$ ECT session). Mauchly's test of sphericity revealed a violation of the assumption of sphericity $\left[\chi^{2}(2)=69.694\right.$, $\mathrm{P}=0.011]$. Therefore, a Greenhouse-Geisser
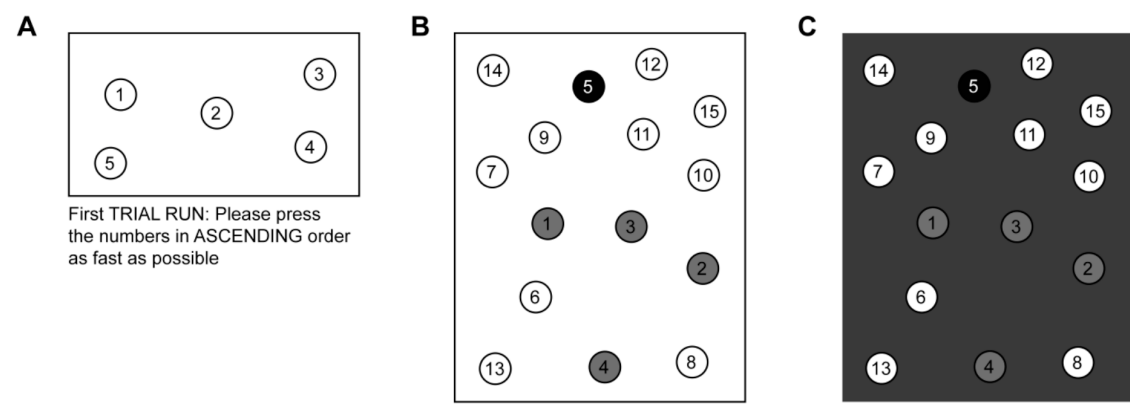

Figure 1. The digital number sorting test. A) A short example test. The explanatory text below the test field was provided in German in the original study but has been translated here for convenience. In the actual tests, this explanation was displayed before the test. B) An actual trail-marking test. The patient taps the grayscale dots to indicate the progress of the task. C) If the patient does not touch the correct number (in this case, the number 6 in the lower left corner), the screen flashes gray as shown. 
correction was used. Testing of within-subjects effects demonstrated that timepoint had no significant effect on performance times $[F(4.428,84.128)=2.318, \mathrm{P}=0.058]$, indicating that no measurable impairment of concentration resulted from single or multiple (up to $3 \times$ ) ECT treatments over the study course. Mean performance times over the course of the study are presented in Figure 3. Controlling for the between-participant factors of gender and age group $(<50 / \geq 50$ years $)$ demonstrated that these factors did not significantly influence performance times $(\mathrm{P}<0.05)$. To assess whether patients with a longer seizure duration elicited by ECT exhibited greater concentration impairment, the covariate mean seizure duration was included in the analysis; however, this covariate also did not significantly affect performance times. Furthermore, controlling for psychopharmaceutical drugs known to potentially cause concentration disturbances (tricyclic antidepressants, mirtazapine, benzodiazepines, and classical antipsychotics) did not reveal any significant impact attributable to such medications (tested using multivariate rmANOVA for those four groups of medications).

To assess whether the repetition of the task influenced performance times via training, we analyzed control subjects' performance times for two consecutive measurements ( $\mathrm{t} 0$ and $\mathrm{t} 1$ ). The mean normalized reaction time was $0.87 \mathrm{sec}$ at $\mathrm{t} 1$ (SD 0.20) compared with $1.0 \mathrm{sec}$ at $\mathrm{t} 0$. The rmANOVA results revealed a statistically significant effect of timepoint $[F(1.0$, $19.0)=8.254, \mathrm{P}=0.010]$, suggesting that a training effect may have led to improvement in the performance times observed after ECT.

The performance times at the first measurement time points after ECT (t1.1, t2.1, and t3.1) tended to be equal to or slightly longer than those at $\mathrm{t} 0$. Given the aforementioned training effect, this phenomenon may be attributable to the expected worsening of concentration due to ECT treatment. However, performance times improved to values below 1 for subsequent measurements after all three ECT sessions, suggesting a rapid recovery from any possible effect of ECT on concentration performance.

\section{Beck's depression inventory}

The mean BDI declined from 27.37 at the first ECT session to 23.53 at the third session; however, this decrease was not statistically significant $\quad[\mathrm{F}(1.434$, 25.811) $=2.897, \mathrm{P}=0.088$ ].

\section{Discussion}

The current literature provides insufficient information regarding the degree of cognitive impairment experienced during and after ECT. This shortcoming is largely attributable to the subjective nature of patient reports and/or the inflexibility of the tests that have been administered (pen-andpaper and/or interviewer-based measurements with the possibility of inter-raterbiased results).13,32-34 Our goal was to use a hand-held device-based test that is easy to apply and sensitive for cognitive functioning in adult depressed patients during a course of ECT treatment.
Surprisingly, our study did not detect significant short-term cognitive deficits. Sedative medication administered in parallel to ECT (e.g., benzodiazepine) and age and gender tended not to influence the performance testing results with respect to short-term memory functioning during the course of ECT. Ultimately, the study group was too small to completely rule out the influence of these factors.

In addition to the small sample size of our study and lack of a validation design, weaknesses of our study include the absence of groups of patients with particular risks, such as schizophrenic or geriatric ( $>65$ years of age) patients, who are

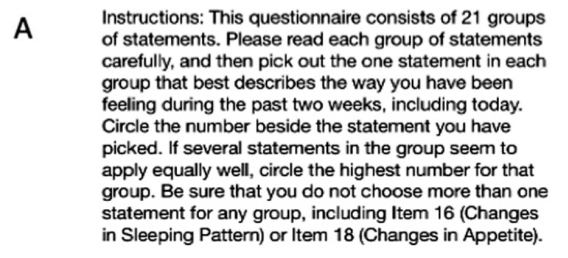

Instructions: This questionnaire consists of 21 groups cat statements group that best describes the way you have been Cling during the past two weeks, including today. picked. If several statements in the group seem to apply equally well, circle the highest number for that statement for any group, including Item 16 (Changes in Sleeping Pattern) or Item 18 (Changes in Appetite).
B

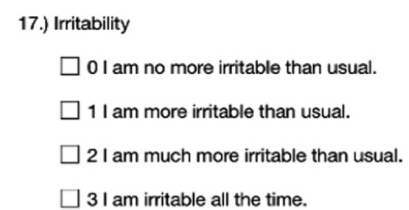

17.) Irritability

2 I am much more irritable than usual.

$\square$ I am irritable all the time.

Decline

Figure 2. The hand-held BDI. In the BDI, similarly to the number sorting test, the displayed text was originally in German but has been translated here. A) Explanation and introduction. B) BDI question 17 (presented as an example). The patient can navigate between questions using the buttons on the bottom of the page.

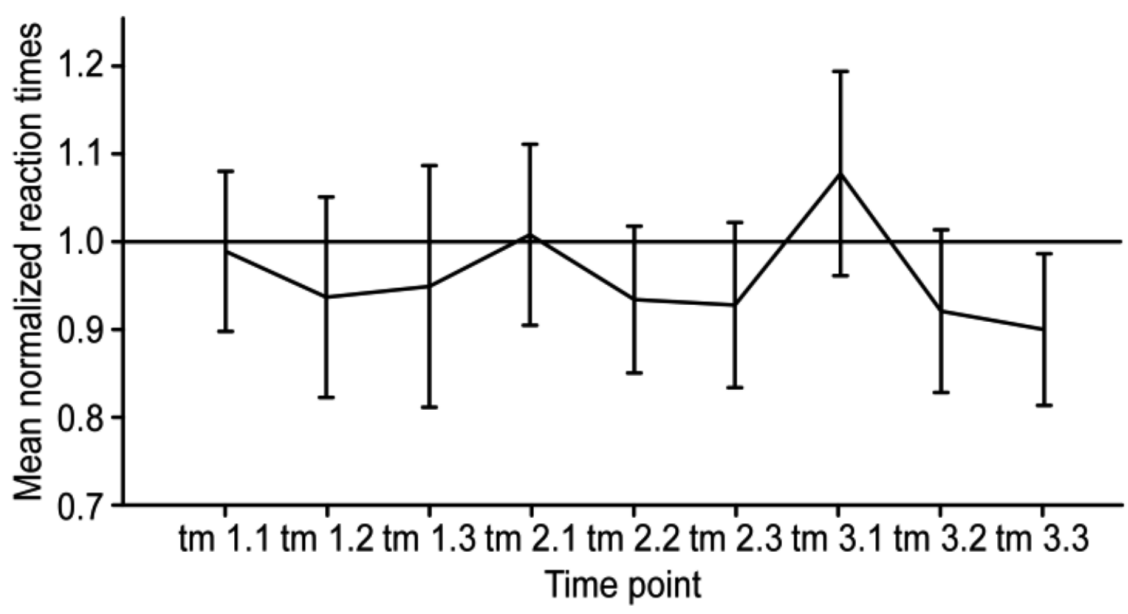

Figure 3. Mean post-ECT performance times throughout the study. Three post-treatment measurements were obtained during each ECT treatment day (e.g., t1.1=first treatment day, first measurement). All values are normalized to the baseline measurement $t 0=1$ (black line). The majority of the reaction time values are located below the reference line, indicating no cognitive disturbance after ECT. 
allegedly at a high risk of experiencing memory and concentration deficits due to ECT.18,19,35-37 Furthermore, participants with known neurocognitive deficits were not examined. The resilient findings for the group of middle-aged patients examined in this study, which included no observed effects of ECT on speed of processing contrast with the results of other investigations. $32,38,39$

With respect to clinical practice, our findings emphasize the importance of more carefully educating patients regarding the likelihood and nature of the hypothesized neurocognitive side effects of ECT, which (according to some small previous examinations 40 and our study) might be less common and severe than previously assumed. Our results also strongly indicate that this iPad-based measurement approach is a useful and easy-to-use tool for daily practice in the monitoring of ECT patients.

Randomized controlled trials, particularly those involving defined risk groups (most notably geriatric and schizophrenic patients), that address ECT-associated neurocognitive impairment are needed to reproduce our findings. ${ }^{26}$

These future studies should include an extensive cognitive test battery for the detailed assessment of cognitive deficits during ECT, which was not extensively performed in our examination due to the small sample size and reduced test battery. In addition, the further subtyping of cognitive impairment is needed and may facilitate the screening of patients who may be at risk for cognitive side effects of ECT, thereby contributing to more tailored ECT treatment and better monitoring of this therapy's typical side effects.

\section{References}

1. Kellner $\mathrm{CH}$, Greenberg RM, Murrough JW, et al. ECT in treatment-resistant depression. Am J Psychiatry 2012;169: 1238-44.

2. Alonso J, Angermeyer MC, Bernert S, et al. Prevalence of mental disorders in Europe: results from the European study of the epidemiology of mental disorders (ESEMeD) project. Acta Psychiatr Scand 2004;109:21-7.

3. Bschor T, Bauer M, Adli M. Chronic and treatment resistant depression: diagnosis and stepwise therapy. Dtsch Arztebl Int 2014;111:766-75.

4. Bschor T. Therapy-resistant depression. Expert Rev Neurother 2010;10:77-86.

5. Souery D, Papakostas GI, Trivedi MH. Treatment-resistant depression. J Clin Psychiatry 2006;67:16-22.
6. Trivedi MH, Kleiber BA. Using treatment algorithms for the effective management of treatment-resistant depression. J Clin Psychiatry 2001;62:25-9.

7. Bourgon LN, Kellner CH. Relapse of depression after ECT: a review. J ECT 2000;16:19-31

8. Pagnin D, de Queiroz V, Pini S, Cassano GB. Efficacy of ECT in depression: a meta-analytic review. J ECT 2004;20:13-20.

9. Eschweiler GW, Vonthein R, Bode R, et al. Clinical efficacy and cognitive side effects of bifrontal versus right unilateral electroconvulsive therapy (ECT): a short-term randomised controlled trial in pharmaco-resistant major depression. J Affect Disord 2007;101:149-57.

10. Gábor G, László T. [The efficacy of ECT treatment in depression: a metaanalysis]. Psychiatr Hung 2005;20:195200. [Article in Hungarian]

11. UK ECT Review Group. Efficacy and safety of electroconvulsive therapy in depressive disorders: a systematic review and meta-analysis. Lancet 2003;361:799-808.

12. Dunne RA, McLoughlin DM. Systematic review and meta-analysis of bifrontal electroconvulsive therapy versus bilateral and unilateral electroconvulsive therapy in depression. World J Biol Psychiatry 2012;13:248-58.

13. Prudic J. Strategies to minimize cognitive side effects with ECT: aspects of ECT technique. J ECT 2008;24:46-51.

14. Sidhom E, Youssef NA. Ultra-brief pulse unilateral ECT is associated with less cognitive side effects. Brain Stimul 2014;7:768-9.

15. Datka W, Siwek M, Dudek D, et al. [Working memory disturbances in patients with major depression after ECT treatment]. Psychiatr Pol 2007;41:339-49. [Article in Polish].

16. Kellner $\mathrm{CH}$, McClintock SM, McCall $\mathrm{WV}$, et al. Brief pulse and ultrabrief pulse right unilateral electroconvulsive therapy (ECT) for major depression: efficacy, effectiveness, and cognitive effects. J Clin Psychiatry 2014;75:777.

17. Maric NP, Stojanovic Z, Andric S, et al. The acute and medium-term effects of treatment with electroconvulsive therapy on memory in patients with major depressive disorder. Psychol Med 2016;46:797-806.

18. Spaans HP, Kho KH, Verwijk E, et al. Efficacy of ultrabrief pulse electroconvulsive therapy for depression: a systematic review. J Affect Disord 2013;150:720-6.

19. Spaans HP, Verwijk E, Comijs HC, et al. Efficacy and cognitive side effects after brief pulse and ultrabrief pulse right unilateral electroconvulsive therapy for major depression: a randomized, double-blind, controlled study. J Clin Psychiatry 2013;74:e1029-36.

20. Delva NJ, Brunet D, Hawken ER, et al. Electrical dose and seizure threshold: relations to clinical outcome and cognitive effects in bifrontal, bitemporal, and right unilateral ECT. J ECT 2000;16: 361-9.

21. Loo C, Sheehan P, Pigot M, Lyndon W. A report on mood and cognitive outcomes with right unilateral ultrabrief pulsewidth $(0.3 \mathrm{~ms})$ ECT and retrospective comparison with standard pulsewidth right unilateral ECT. J Affect Disord 2007;103:277-81.

22. Kellner $\mathrm{CH}$. The cognitive effects of ECT: bridging the gap between research and clinical practice. Convuls Ther 1996;12:133-5.

23. Sackeim HA, Ross FR, Hopkins N, et al. Subjective side effects acutely following ECT: associations with treatment modality and clinical response. Convuls Ther 1987;3:100-10.

24. Peretti CS, Danion JM, Grangé D, Mobarek N. Bilateral ECT and autobiographical memory of subjective experiences related to melancholia: a pilot study. J Affect Disord 1996;41:9-15.

25. Abrams R. Does bilateral ECT cause persistent cognitive impairment? J ECT 2007;23:61-2.

26. Feliu M, Edwards CL, Sudhakar S, et al. Neuropsychological effects and attitudes in patients following electroconvulsive therapy. Neuropsychiatr Dis Treat 2008;4:613-7.

27. Preuschoff I, Müller HH, Sperling W, et al. iPad-assisted measurements of duration estimation in psychiatric patients and healthy control subjects. PLOS One 2013;8:e61295.

28. Tombaugh TN. Trail making test A and B: normative data stratified by age and education. Arch Clin Neuropsychol 2004;19:203-14.

29. Adler D, Gorelick D, Rummans TA, et al. Practice guideline for the treatment of patients with major depressive disorder (revision). Am J Psychiatry 2000;157:1-45.

30. Parsons OA, Maslow HI, Morris F, Denny JP. Trail-making test performance in relation to certain experimenter, test and subject variables. Percept Mot Skills 1964;19:199-206.

31. Burkhart BR, Rogers K, McDonald WD, et al. The measurement of depression: enhancing the predictive validity of the beck depression inventory. J Clin Psychol 1984;40:1368-72. 
32. Prudic J, Peyser S, Sackeim HA. Subjective memory complaints: a review of patient self-assessment of memory after electroconvulsive therapy. J ECT 2000;16:121-32.

33. Sackeim HA, Luber B, Moeller JR, et al. Electrophysiological correlates of the adverse cognitive effects of electroconvulsive therapy. J ECT 2000;16: 110-20.

34. Verwijk E, Comijs HC, Kok RM, et al. Neurocognitive effects after brief pulse and ultrabrief pulse unilateral electroconvulsive therapy for major depression: a review. J Affect Disord 2012;140:233-43.

35. Wang WZ, Pu CC, Jiang JL, et al. Efficacy and safety of treating patients with refractory schizophrenia with antipsychotic medication and adjunctive electroconvulsive therapy: a systematic review and meta-analysis. Shanghai Arch Psychiatry 2015;27:206-19.

36. Iancu I, Pick N, Seener-Lorsh O, Dannon P. Patients with schizophrenia or schizoaffective disorder who receive multiple electroconvulsive therapy sessions: characteristics, indications, and results. Neuropsychiatr Dis Treat 2015;11:853-62.

37. Oremus C, Oremus M, McNeely H, et al. Effects of electroconvulsive therapy on cognitive functioning in patients with depression: protocol for a systematic review and meta-analysis. BMJ Open 2015;5:e006966.
38. Ingram A, Saling MM, Schweitzer I. Cognitive side effects of brief pulse electroconvulsive therapy: a review. J ECT 2008;24:3-9.

39. Crowley K, Pickle J, Dale R, Fattal O. A critical examination of bifrontal electroconvulsive therapy: clinical efficacy, cognitive side effects, and directions for future research. J ECT 2008;24:268-71.

40. Hausner L, Damian M, Sartorius A, Frölich L. Efficacy and cognitive side effects of electroconvulsive therapy (ECT) in depressed elderly inpatients with coexisting mild cognitive impairment or dementia. J Clin Psychiatry 2011;72:91-7. 